\title{
A prestação de cuidados de saúde no horizonte da modernidade
}

Rev Port Imunoalergologia 20I9;27 (I): 7 -8

Joana Caiado

A abordagem prática da hipersensibilidade a meios de contraste é atualmente um dos grandes desafios na área da alergia medicamentosa, sendo muitas vezes necessário tomar decisões em curto espaço de tempo. Muitos são os atos em que o contraste é fundamental, como é o caso da tomografia computorizada ou da angiografia coronária, verificando-se um reconhecimento e referenciação crescentes dos doentes com reações a meios de contraste, quer reações imediatas quer não imediatas.

O não encaminhamento dos doentes a uma consulta de Imunoalergologia após uma reação a meios de contraste pode colocar em risco a evolução destes doentes: no caso de o doente referir reação prévia pode haver uma recusa na utilização de meio de contraste em exames diagnósticos ou mesmo terapêuticos por receio e, por outro lado, a omissão ou não valorização de reação prévia pode conduzir a um risco aumentado de nova ocorrência tão ou mais grave que a anterior.

A dificuldade diagnóstica prende-se com a diversidade de apresentações clínicas, timing da reação e ao facto de não haver um consenso global relativamente à escalada diagnóstica e aos planos de pré-medicação (quer sejam doentes de risco ou com reação prévia), sendo que atualmente cada hospital e/ou serviço tem as suas recomendações próprias. Há assim necessidade de uniformizar protocolos de abordagem diagnóstica e terapêutica.
Como atual Coordenadora do Grupo de Interesse de Alergia a Fármacos (GIAF), não poderia deixar de congratular os autores destes excelentes trabalhos.

O artigo de revisão efetuado pelo Dr. João Marcelino e cols. denota a disparidade na valorização dos testes diagnósticos, especialmente dos in vitro, dado não serem ainda reconhecidos como meios alternativos, sendo mais consensual que a avaliação diagnóstica passe pela realização de testes intradérmicos com as concentrações não irritativas já publicadas (testes cutâneos em picada raramente positivos). Já em relação à prova de provocação, gold-standard no diagnóstico de alergia medicamentosa, apesar de não ser ainda uma abordagem globalmente aceite, há já vários grupos que defendem ser esta a única forma de demonstrar a tolerância clínica ao meio de contraste que afirmamos ser alternativo e seguro.

O artigo da Dra. Cristina Lopes e cols. tem como objetivo apresentar um protocolo por consenso de peritos em várias especialidades que diretamente tratam doentes com reações agudas de hipersensibilidade a meios de contraste (Imagiologia, Imunoalergologia e Medicina Intensiva). Um dos pontos de realce deste artigo é a chamada de atenção para a importância da estratificação de risco nestes doentes, a qual vai definir a estratégia de profilaxia, de acordo com o risco, que pode ser baixo, médio ou alto. Outra questão 
importante focada neste artigo é a necessidade de registar o tipo de reação, e acima de tudo o meio de contraste utilizado. Aborda ainda um algoritmo de tratamento de reações muito organizado, que deverá estar sempre presente em todas as salas de imagiologia e de hemodinâmica.
Considero este artigo muito útil do ponto de vista prático para a uniformização da abordagem inicial das reações a meios de contraste.

Mais uma vez, parabéns aos autores!

Joana Caiado

Assistente Hospitalar Graduada, Hospital de Santa Maria, CHULN Coordenadora do GIAF 